\title{
(2) OPEN ACCESS \\ Income and neighbourhood deprivation in relation to obesity in urban dwelling children $0-12$ years of age: a cross-sectional study from 2013 to 2019
}

\author{
Laura N Anderson (D) , ${ }^{1,2}$ Tooba Fatima, ${ }^{1}$ Bindra Shah, ${ }^{1}$ Brendan T. Smith (D) , 3,4 \\ Anne E. Fuller (D) , 1,5 Cornelia M Borkhoff, 2,4 Charles D G Keown-Stoneman, 4,6 \\ Jonathon L. Maguire, 4,5,6,7 Catherine S. Birken 2,5,7,8
}

\begin{abstract}
- Additional supplemental material is published online only. To view, please visit the journal online (http://dx. doi.org/10.1136/jech-2021216455)
\end{abstract}

${ }^{1}$ Health Research Methods, Evidence, and Impact, McMaster University, Hamilton, Ontario, Canada

${ }^{2}$ Child Health Evaluative Sciences, The Hospital for Sick Children Research Institute, Toronto, Ontario, Canada ${ }^{3}$ Public Health Ontario, Toronto, Ontario, Canada

${ }^{4}$ Dalla Lana School of Public Health, University of Toronto, Toronto, Ontario, Canada ${ }^{5}$ Department of Pediatrics, University of Toronto, Toronto, Ontario, Canada

${ }^{6}$ Li Ka Shing Knowledge Institute, St. Michael's Hospital, Toronto, Ontario, Canada ${ }^{7}$ Department of Nutritional Sciences, University of Toronto, Toronto, Ontario, Canada ${ }^{8}$ Paediatric Medicine, The Hospital for Sick Children, Toronto, Ontario, Canada

\section{Correspondence to}

Dr Laura N Anderson, Health Research Methods, Evidence, and Impact, McMaster University, Hamilton, Canada; LN.Anderson@mcmaster.ca

Received 13 January 2021 Accepted 8 August 2021 Published Online First 6 September 2021

\section{Check for updates}

(C) Author(s) (or their employer(s)) 2022. Re-use permitted under CC BY-NC. No commercial re-use. See rights and permissions. Published by BMJ.

To cite: Anderson LN, Fatima T, Shah B, et al. J Epidemiol Community Health 2022:76:274-280

\section{ABSTRACT}

Background Childhood obesity is a major public health concern. This study evaluated the independent and joint associations of family-level income, neighbourhood-level income and neighbourhood deprivation, in relation to child obesity.

Methods A cross-sectional study was conducted in children $\leq 12$ years of age from TARGet Kids! primary care network (Greater Toronto Area, 2013-2019). Parent-reported family income was compared with median neighbourhood income and neighbourhood deprivation measured using the Ontario Marginalization Index. Children's height and weight were measured and body mass index (BMI) z-scores (zBMI) were calculated. ORs and $95 \%$ Cls were estimated for the three exposure variables separately using multilevel multinomial logistic regression models with $\mathrm{zBMI}$ categories as the outcome, adjusting in model 1 for age, sex, ethnicity and number of family members and in model 2 adding family income. A joint measure was derived combining income and deprivation measures.

Results A total of 5962 children were included. Low family income (Q1 vs Q5: OR=4.69, 95\% Cl 2.65 to 8.29), low neighbourhood income (Q1 vs Q5: $O R=2.18$, $95 \% \mathrm{Cl} 1.33$ to 3.58 ) and high neighbourhood deprivation (Q1 vs Q5: OR=2.45, 95\% Cl 1.52 to 3.95) were each associated with increased OR of child obesity. However, after adjustment for family income, the association for both neighbourhood income $(\mathrm{OR}=1.39$, $95 \% \mathrm{Cl} 0.82$ to 2.34$)$ and deprivation $(\mathrm{OR}=1.56,95 \% \mathrm{Cl}$ 0.94 to 2.58 ) and obesity was attenuated. Children from low-income families living in low-income or high deprivation neighbourhoods had higher OR of obesity. Conclusion Child obesity was independently associated with low family-level income and a joint measure suggests that neighbourhood also matters. Socioeconomic inequalities at both individual and neighbourhood levels should be addressed in childhood obesity interventions.

\section{BACKGROUND}

Childhood obesity is a major public health concern and recent estimates from Canada and the USA suggest that $13 \%$ and $18.5 \%$ of children, respectively, have obesity. ${ }^{12}$ Obesity in childhood is a risk factor for obesity and other chronic diseases across the life course. Treatment of child obesity is challenging ${ }^{3}$ and a broad approach to understanding the wide range of socioecological risk factors is important to inform population health interventions and prevention. ${ }^{4}$ Lower socioeconomic position, broadly defined as low family income, parental education, occupation or living space, was associated with a significant increased OR of both overweight $(\mathrm{OR}=1.10,95 \% \mathrm{CI} 1.03$ to 1.17$)$ and obesity $(\mathrm{OR}=1.41,95 \% \mathrm{CI} 1.29$ to 1.55$)$ in a metaanalysis of 63 studies in children aged $0-15$ years. ${ }^{5}$

Income is one of the many social determinants of health that strongly influences health and health-related behaviours across the life trajectory. Income can be measured at the family level (or individual level) and area level with each representing a distinct construct. ${ }^{67}$ For example, familylevel income measures family finances, whereas area-level income represents neighbourhood resources and opportunities. ${ }^{8}$ Area-level measures of income, such as median neighbourhood income, are commonly used as a proxy when family-level income data are not available, such as when using administrative data. ${ }^{9}$ However, in North America, the agreement between family-level and areaincome measures is generally poor with weighted kappa values between 0.11 and 0.22 and misclassification ranging from $20 \%$ to $80 \% .^{671011}$ Neighbourhood income can also be an indicator of other neighbourhood characteristics that may affect child health, including neighbourhood social and physical infrastructure. ${ }^{12} 13$ To better understand these factors, more comprehensive measures of area-level material deprivation can also be used. ${ }^{14}$ Material deprivation is a score that uses neighborhood-level data and takes into consideration additional neighbourhood characteristics beyond income, such as area-level measures of housing, education and family structure. ${ }^{14}$

Previous US studies have found low agreement between individual-level and neighbourhoodlevel income measures, but both high individual and high neighbourhood income were associated with reduced OR of child overweight when evaluated separately. ${ }^{10}{ }^{11}$ However, elsewhere a significant interaction between family-level and neighbourhood-level income has suggested that children with higher early childhood family income were at low risk of obesity in low deprivation but not high deprivation neighbourhoods. ${ }^{15}$ The independent and discordant associations between familylevel income and neighborhood-level income and 
deprivation with child obesity among young children in Canada are unknown.

The primary objective of this study was to evaluate the independent and combined associations of family-level income, neighbourhood-level income and neighbourhood deprivation, with child obesity among children $\leq 12$ years of age recruited from primary care practices in the Greater Toronto Area, Canada. A secondary objective was to report the agreement between family-level income, neighbourhood-level income and neighbourhood deprivation in our study population.

\section{METHODS}

\section{Study design and sample population}

A cross-sectional study was conducted in children $0-\leq 12$ years of age participating in The Applied Research Group for Kids (TARGet Kids!). TARGet Kids! is a community-based, primary care research network. Since 2008, children $<6$ years of age at time of enrolment were recruited by trained research assistants embedded in primary care paediatric and family medicine clinics and followed annually. The study protocol and population characteristics have been described previously. ${ }^{16}$ TARGet Kids! exclusion criteria at enrolment are: $<32$ weeks gestational age; diagnosed with conditions affecting growth; chronic conditions (except for asthma); severe developmental delay and parents not able to complete English questionnaires. Children $>12$ years of age were excluded since there were relatively few in our study population and adolescents may differ from children. For this study, children were included if they had a study visit between September 2013 and March 2019 with complete data on the exposure (family and neighbourhood income) and outcome variables (obesity) and if they were recruited from 1 of the 10 sites in the Greater Toronto Area, Canada.

\section{Measures}

Family income

Family-level income was self-reported by parents using a standardised questionnaire that asked, 'What was your family income before taxes last year?' (response options: 13 binned categories, ranging from 'less than $\$ 10000$ ' to 'greater than $\$ 500000$ '). For the purpose of this analysis, self-reported family-level income was transformed from a categorical variable into a continuous measure by running a 'binsmooth' procedure ${ }^{17}$ in $\mathrm{R}$ to estimate a cumulative distribution function that allows for the random imputation of continuous measures for a variable that is originally contained in binned categories. ${ }^{18}$

\section{Neighbourhood income}

Neighbourhood income was measured using the median before-tax family-level income that was collected by Statistics Canada for the 2016 Canadian Census. Median neighbourhood income was defined as the median income of the dissemination areas where the participant lived; dissemination areas are geographic areas with an average population of 400-700 people. The 2016 Canadian Census data were linked to TARGet Kids! data using the postal code conversion file and used to identify the median income of the neighbourhoods. The postal code conversion file provides correspondence between 6-digit postal codes and standard geographic areas for which census data are reported. ${ }^{19}$ Both family-level and neighbourhood-level incomes were categorised into quintiles defined within our study population with the lowest quintile being the lowest income category and the highest quintile as the highest income category.

\section{Material deprivation}

Material deprivation was measured using the Ontario Marginalization Index (ON-Marg), an area-based index that was developed to measure inequalities. ${ }^{20}$ Material deprivation, which is one of the four components of the validated ON-Marg Index, was included in this study as it is closely related to poverty and measures risk factors for inability to access and attain material needs. The material deprivation measure includes the following variables measures at the dissemination area from the 2016 Canadian census: high school graduation, lone parent families, government transfer payments, unemployment, low income and dwellings in need of major repairs. ${ }^{20}$ Material deprivation is reported in externally derived quintiles for Ontario; for the purpose of this analysis and for consistency with our income measures, the first quintile was coded as being the most deprived (ie, the lowest socioeconomic status (SES) category) and the fifth quintile as the least deprived. ON-Marg data were linked to TARGet Kids! data using the postal code conversion file which linked 6-digit postal codes from TARGet Kids! to dissemination areas.

\section{Measurement of child body mass index (BMI)}

Children's height (or length for children less than 2 years of age) and weight were measured at each study visit by trained research staff using standardised procedures. BMI z-scores (zBMI) were calculated and defined using the WHO recommendations. ${ }^{21}$ The WHO SD score definitions for children $>5$ years were used to categorise weight status as follows: underweight: $<-2$; normal: $-2-\leq 1$; overweight $>1-\leq 2$ and obesity: $>2$. Children from age 0 to $\leq 12$ years of age were included in our study and we applied the WHO z-score definitions for children $>5$ years of age to all children regardless of their age for consistency and zBMI were used for all ages. ${ }^{22} 23$

\section{Potential confounders}

All confounders were selected a priori based on previous literature. Selected confounders included child age, child sex, maternal ethnicity and number of family members. Maternal ethnicity was collected using 20 category response options and was collapsed into three for the purpose of the analysis (European, East/South/Southeast Asian and other), due to small cell sizes for many response options. Number of family members was defined as the total number of adults and children supported by the family income.

\section{Statistical analysis}

Descriptive statistics for exposure, outcome, confounding and other variables were calculated using mean and SD for continuous variables and frequency distributions for categorical variables. For the primary analysis, a multilevel multinomial logistic regression model was constructed using the generalised linear mixed models (GLIMMIX) procedure in SAS to evaluate the independent association of each of the three exposure variables (familylevel income, neighbourhood-level income and neighbourhood deprivation) with the four zBMI categories, adjusting for the nested nature of self-reported family-level and neighbourhoodlevel income data. First, separate models were calculated for each of the three exposures adjusted only for child age, child sex, maternal ethnicity and number of family members and clustering by neighbourhood (model 1). Subsequently, models were calculated for each of the three exposures adjusted for the same variables as in model 1 plus the additional adjustment for both income variables (model 2). To evaluate the joint associations, 
two new variables were created using the following discordant and concordant combinations of low (Q1) and higher (Q2-Q5) categories: (1) family income and neighbourhood income with response options: low/low, low/higher, higher/low and higher/ higher and (2) family income and neighbourhood deprivation with response options: low/low, low/higher, higher/low and higher/higher. We conducted sensitivity analysis evaluating alternate definitions of lower and higher categories, such as Q1 and Q2 versus Q3-Q5. The corresponding ORs and 95\% CIs were estimated using multilevel multinomial logistic regression models adjusted for child age, child sex, maternal ethnicity and number of family members and clustering by neighbourhood (model 1). Because of known differences in child obesity by sex, ${ }^{24}$ all analyses conducted were also stratified by sex. Interactions with age and sex were considered for each exposure measure. For the secondary objective, the agreement between each measure of income and deprivation was evaluated using weighted kappa statistics. All analyses were conducted using SAS V.9.4 statistical software (SAS Institute). ${ }^{25}$

Quantitative bias analysis was conducted to evaluate the potential impact of selection bias on the observed associations. Quantitative bias analysis was conducted only for selection bias as it was thought to be the major source of bias in this study. It was hypothesised that families with low versus high income may differentially choose to participate based on whether their child had obesity and previous TARGet Kids! studies have shown that the mean income among study participants was relatively high compared with the city of Toronto. Simple bias analysis was conducted ${ }^{26}$ and parameters for the bias analysis were estimated using national data on older children from the Canadian Community Health Study. Lastly, the potential for unmeasured or uncontrolled confounding was evaluated using the E-value formula $E_{O R}=O R+\sqrt{O R \times(O R-1)} \cdot{ }^{27}$

\section{RESULTS}

A total of 5962 children enrolled in the TARGet Kids! cohort were included. The mean age of children in this study was 41.4 months (approximately 3.5 years), $48 \%$ were female and $52 \%$ were male and $62 \%$ reported maternal ethnicity as European (table 1). Family and neighbourhood income quintiles and the corresponding cut-points are described in table 1. The spread between highest and lowest quintile was much greater for family income (> $\$ 221438$ vs $<\$ 70244)$ compared with neighbourhood income ( $>\$ 116607$ vs $<$ \$62 336). Using the ON-Marg defined quintiles for material deprivation, $14 \%$ of children were in the highest deprivation quintile, while $29 \%$ were in the lowest deprivation quintile. Approximately 4\% of children were underweight, $12 \%$ were overweight and $4 \%$ had obesity. Overweight and obesity were slightly higher in boys compared with girls ( $12 \%$ vs $11 \%$, and $4 \%$ vs $3 \%$, respectively).

Figure 1 describes the proportion of children with obesity by family income, neighbourhood income and deprivation quintile and shows that the lowest quintile across all three exposure variables has the highest proportion of children with obesity. Table 2 summarises results from the multilevel multinomial logistic regression model separately for the associations between family income, neighbourhood income and neighbourhood deprivation (model 1) and for models adjusted for both family and neighbourhood measures (model 2). Family income (model 1: Q1 vs Q5, OR=4.69, 95\% CI 2.65 to 8.29), neighbourhood income (model 1: Q1 vs $\mathrm{Q} 5, \mathrm{OR}=2.18,95 \% \mathrm{CI} 1.33$ to 3.58 ) and neighbourhood
Table 1 Baseline sociodemographic characteristics of TARGet Kids! Study participants for total study sample and by sex

\begin{tabular}{|c|c|c|c|}
\hline & $\begin{array}{l}\text { Overall } \\
(\mathrm{N}=5962)\end{array}$ & $\begin{array}{l}\text { Males } \\
(\mathrm{n}=3117)\end{array}$ & $\begin{array}{l}\text { Females } \\
(n=2845)\end{array}$ \\
\hline Variable & Mean (SD) & Mean (SD) & Mean (SD) \\
\hline Age (in months) & 41.35 (37.13) & $41.43(36.89)$ & $41.26(37.41)$ \\
\hline \multirow{2}{*}{$\begin{array}{l}\text { Number of family members } \\
\text { supported by family income }\end{array}$} & $3.64(1.08)$ & $3.66(1.07)$ & $3.62(1.08)$ \\
\hline & $\mathrm{N}(\%)$ & $\mathrm{N}(\%)$ & $\mathrm{N}(\%)$ \\
\hline \multicolumn{4}{|l|}{ Child sex } \\
\hline Male & $3117(52.28 \%)$ & & \\
\hline Female & $2845(47.72 \%)$ & & \\
\hline \multicolumn{4}{|l|}{ Maternal ethnicity } \\
\hline European & $3360(62.36 \%)$ & $\begin{array}{l}1755 \\
(62.21 \%)\end{array}$ & $\begin{array}{l}1605 \\
(62.52 \%)\end{array}$ \\
\hline East/South/Southeast Asian & $1116(20.71 \%)$ & $599(21.23 \%)$ & $517(20.14 \%)$ \\
\hline Other & $912(16.93 \%)$ & $467(16.55 \%)$ & $445(17.34 \%)$ \\
\hline \multicolumn{4}{|l|}{ Maternal education } \\
\hline$<$ University & $1301(22.07 \%)$ & $660(21.44 \%)$ & $641(22.76 \%)$ \\
\hline$\geq$ University & $4593(77.93 \%)$ & $\begin{array}{l}2418 \\
(78.56 \%)\end{array}$ & $\begin{array}{l}2175 \\
(77.24 \%)\end{array}$ \\
\hline \multicolumn{4}{|l|}{ Child BMI categories } \\
\hline Underweight $(z B M \mid<-2)$ & $255(4.28 \%)$ & $135(4.33 \%)$ & $120(4.22 \%)$ \\
\hline Normal weight $(-2 \leq \mathrm{zBMI} \leq 1)$ & $4785(80.26 \%)$ & $\begin{array}{l}2457 \\
(78.83 \%)\end{array}$ & $\begin{array}{l}2328 \\
(81.83 \%)\end{array}$ \\
\hline Overweight $(1<z \mathrm{BMI} \leq 2)$ & $705(11.82 \%)$ & $391(12.54 \%)$ & $314(11.04 \%)$ \\
\hline Obesity (zBMI >2) & $217(3.64 \%)$ & $134(4.30 \%)$ & $83(2.92 \%)$ \\
\hline \multicolumn{4}{|l|}{ Family income categories (\$C) } \\
\hline Q1 (<\$70244) & $1192(20.0 \%)$ & $592(19.0 \%)$ & $600(21.1 \%)$ \\
\hline Q2 (\$70244-1 16236) & $1193(20.0 \%)$ & $654(21.0 \%)$ & $539(19.0 \%)$ \\
\hline Q3 (\$1 16237-1 63081) & $1192(20.0 \%)$ & $622(20.0 \%)$ & $570(20.0 \%)$ \\
\hline Q4 (\$1 63 082-221 438) & $1192(20.0 \%)$ & $634(20.3 \%)$ & $558(19.6 \%)$ \\
\hline Q5 (>\$221 438) & $1193(20.0 \%)$ & $615(19.7 \%)$ & $578(20.3 \%)$ \\
\hline \multicolumn{4}{|c|}{ Median neighbourhood income categories (\$C) } \\
\hline Q1 (<\$62336) & $1186(19.9 \%)$ & $622(20.0 \%)$ & $564(19.8 \%)$ \\
\hline Q2 (\$62 336-80383) & $1190(20.0 \%)$ & $600(19.3 \%)$ & $590(20.7 \%)$ \\
\hline Q3 (\$80384-96109) & $1200(20.0 \%)$ & $632(20.3 \%)$ & $568(20.0 \%)$ \\
\hline Q4 (\$96110-1 16607) & $1186(19.9 \%)$ & $637(20.4 \%)$ & $549(19.3 \%)$ \\
\hline Q5 (>\$116607) & $1200(20.1 \%)$ & $626(20.1 \%)$ & $574(20.2 \%)$ \\
\hline \multicolumn{4}{|c|}{ Material deprivation (ON-Marg quintiles) } \\
\hline Q1 (most deprived) & $845(13.8 \%)$ & $429(13.8 \%)$ & $416(14.6 \%)$ \\
\hline Q2 & $893(15.0 \%)$ & $466(15.0 \%)$ & $427(15.0 \%)$ \\
\hline Q3 & $1167(19.2 \%)$ & $598(19.2 \%)$ & $569(20.0 \%)$ \\
\hline Q4 & $1365(23.6 \%)$ & $736(23.6 \%)$ & $629(22.1 \%)$ \\
\hline Q5 (least deprived) & $1691(28.5 \%)$ & $888(28.5 \%)$ & $803(28.2 \%)$ \\
\hline
\end{tabular}

BMI, body mass index; \$C, Canadian dollars; ON-Marg, Ontario Marginalization Index; zBMI, BMI z-scores.

deprivation (model 1: Q1 vs Q5, OR=2.45, 95\% CI 1.52 to 3.95 ) were each strongly associated with child obesity compared with normal weight. The ORs showed a relatively consistent dose-response association across SES quintiles. After adjusting for neighbourhood income (table 3), the association between family income and obesity was attenuated but remained strong (model 2: Q1 vs Q5, OR $=3.97,95 \% \mathrm{CI}$ 2.18 to 7.22 ). In comparison, after adjusting for family income, the OR for the association between neighbourhood 


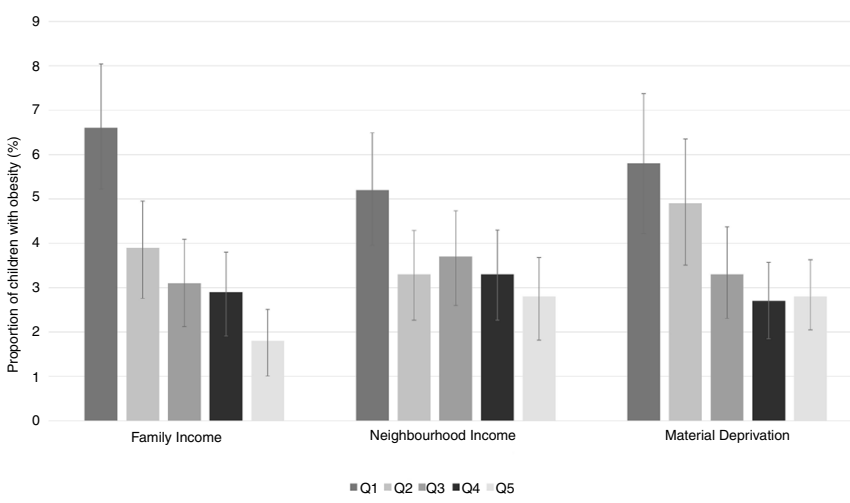

Figure 1 The proportion of children with obesity and $95 \% \mathrm{Cl}$ by family income, neighbourhood income and neighbourhood deprivation quintile.

income and obesity was attenuated and the 95\% CI overlapped with 1.0 (model 2: Q1 vs Q5, OR=1.39, 95\% CI 0.83 to 2.34 ). The association between material deprivation and child obesity was attenuated after adjustment for family income (model 2: Q1 vs Q5, OR=1.56, 95\% CI 0.94 to 2.58 ). Online supplemental table 1 shows results from the model between deprivation and zBMI stratified by sex. Interactions with sex were not statistically significant at a 5\% level of significance; the conclusions were similar in both boys and girls with the exception that low family income was significantly associated reduced risk of underweight among boys but not girls. Similarly, interactions between child age and family income $(p=0.21)$, neighbourhood income $(p=0.44)$ and neighbourhood deprivation $(p=0.61)$ were also not statistically significant.

Table 3 presents the results for the combined variables looking at the discordant and concordant categories of low family income (defined as Q1) versus higher (Q2-Q5) categories of neighbourhood income and deprivation. Children with low family income and low neighbourhood income had a high OR of obesity (OR=3.28, 95\% CI 2.08 to 5.18$)$. The OR of obesity was also high for children with low family income and higher neighbourhood income $(\mathrm{OR}=2.05,95 \% \mathrm{CI} 1.32$ to 3.19$)$, but not for children with higher family income and low neighbourhood income $(\mathrm{OR}=1.37,95 \% \mathrm{CI} 0.84$ to 2.24$)$. Similar findings were observed for the combination of family income and neighbourhood deprivation (table 3 ). Results of sensitivity analysis evaluating low defined as Q1 and Q2 versus higher Q3-Q5 for the discordant analysis were similar, but the ORs were not as strong. For example, for children with low family income and low neighbourhood income, the OR was 2.45 (95\% CI 1.61 to 3.71).

Quantitative bias analysis was conducted to evaluate the potential impact of selection bias on the observed associations. The selection proportions for the quantitative bias analysis for selection bias were estimated using data from the CCHS on income and BMI among older children. We estimated that the selection proportions for exposure $(\mathrm{E})$ and outcome $(\mathrm{O})$ cells $\mathrm{E}+\mathrm{O}+, \mathrm{E}+\mathrm{O}-, \mathrm{E}-\mathrm{O}+$ and $\mathrm{E}-\mathrm{O}-$ were $0.37,0.63,0.83$ and 0.88 yielding a selection bias OR of 0.62 ; this suggests that participants with low income and obesity were about half as likely to

Table 2 Multilevel multinomial logistic regression model for the association between family income, neighbourhood income and underweight, overweight and obesity categories compared with normal weight in children aged 0-12 years

\begin{tabular}{|c|c|c|c|c|c|c|}
\hline \multirow[b]{2}{*}{ Exposure variable } & \multicolumn{3}{|c|}{$\begin{array}{l}\text { Model } 1 \text { (adjusted for child age, sex, number of family } \\
\text { members, maternal ethnicity) } \\
\text { OR ( } 95 \% \mathrm{Cl})\end{array}$} & \multicolumn{3}{|c|}{$\begin{array}{l}\text { Model } 2 \text { (adjusted for all variables in model } 1 \text { plus } \\
\text { adjustment for family or neighborhood-level income } \\
\text { variables)* } \\
\text { OR }(95 \% \mathrm{Cl})\end{array}$} \\
\hline & $\begin{array}{l}\text { Underweight } \\
(\mathrm{zBMI}<-2)\end{array}$ & $\begin{array}{l}\text { Overweight } \\
(1<\mathrm{BMI} \leq 2)\end{array}$ & Obesity (zBMI >2) & $\begin{array}{l}\text { Underweight } \\
(\mathrm{zBMl}<-2)\end{array}$ & $\begin{array}{l}\text { Overweight } \\
(1<z B M I \leq 2)\end{array}$ & Obesity $(\mathrm{zBMI}>2)$ \\
\hline \multicolumn{7}{|l|}{ Family income (\$C) } \\
\hline Q1 (<\$70244) & $0.81(0.51$ to 1.29$)$ & 1.13 (0.85 to 1.51$)$ & 4.69 (2.65 to 8.29$)$ & $0.73(0.45$ to 1.20$)$ & 1.20 (0.89 to 1.62 ) & $4.36(2.40$ to 7.90$)$ \\
\hline Q2 (\$70244-1 16236) & $0.87(0.55$ to 1.37$)$ & 1.02 (0.78 to 1.34$)$ & 2.69 (1.51 to 4.79$)$ & 0.81 (0.51 to 1.28$)$ & 1.06 (0.80 to 1.40$)$ & 2.64 (1.47 to 4.74$)$ \\
\hline Q3 (\$1 16237-1 63081) & 1.12 (0.73 to 1.73$)$ & 1.06 (0.81 to 1.38$)$ & 2.42 (1.35 to 4.34$)$ & 1.07 (0.69 to 1.66$)$ & 1.09 (0.83 to 1.42$)$ & $2.38(1.31$ to 4.30$)$ \\
\hline Q4 (\$1 63 082-221 438) & $0.82(0.51$ to 1.30$)$ & $0.92(0.70$ to 1.20$)$ & 1.72 (0.94 to 3.16$)$ & $0.79(0.49$ to 1.26$)$ & 0.93 (0.71 to 1.22$)$ & 1.71 (0.93 to 3.15$)$ \\
\hline Q5 (>\$221 438) & 1.00 & 1.00 & 1.00 & 1.00 & 1.00 & 1.00 \\
\hline \multicolumn{7}{|c|}{ Neighbourhood-level income (\$C) } \\
\hline Q1 (<\$62336) & 1.26 (0.78 to 2.03$)$ & 0.90 (0.68 to 1.20$)$ & 2.18 (1.33 to 3.58$)$ & $1.38(0.83$ to 2.27$)$ & 0.84 (0.63 to 1.13$)$ & 1.39 (0.83 to 2.34$)$ \\
\hline Q2 (\$62336-80383) & $1.56(0.98$ to 2.50$)$ & 0.87 (0.66 to 1.15$)$ & 1.23 (0.72 to 2.11$)$ & 1.65 (1.02 to 2.67$)$ & 0.84 (0.63 to 1.11$)$ & 0.89 (0.52 to 1.54$)$ \\
\hline Q3 (\$80384-96 109) & 0.95 (0.57 to 1.58$)$ & 0.82 (0.62 to 1.08$)$ & 1.35 (0.80 to 2.30$)$ & 0.98 (0.59 to 1.65$)$ & 0.79 (0.60 to 1.05$)$ & 1.03 (0.60 to 1.76$)$ \\
\hline Q4 (\$96110-1 16607) & 1.49 (0.93 to 2.39$)$ & 0.96 (0.74 to 1.25$)$ & 1.39 (0.83 to 2.32$)$ & 1.54 (0.95 to 2.48$)$ & 0.94 (0.72 to 1.23$)$ & $1.12(0.67$ to 1.89$)$ \\
\hline Q5 (>\$116607) & 1.00 & 1.00 & 1.00 & 1.00 & 1.00 & 1.00 \\
\hline \multicolumn{7}{|c|}{ Material deprivation (quintiles) } \\
\hline Q1 (most deprived) & $1.08(0.67$ to 1.74$)$ & 1.33 (0.99 to 1.78 ) & 2.45 (1.52 to 3.95$)$ & 1.14 (0.68 to 1.89$)$ & 1.29 (0.95 to 1.76$)$ & $1.56(0.94$ to 2.58$)$ \\
\hline Q2 & 1.22 (0.77 to 1.94$)$ & 1.11 (0.83 to 1.47$)$ & 1.75 (1.08 to 2.83$)$ & 1.26 (0.79 to 2.03$)$ & 1.09 (0.81 to 1.50$)$ & 1.29 (0.79 to 2.11$)$ \\
\hline Q3 & $1.27(0.82$ to 1.96$)$ & 1.11 (0.86 to 1.44 ) & 1.32 (0.82 to 2.12$)$ & 1.31 (0.84 to 2.05 ) & 1.10 (0.85 to 1.43$)$ & $1.03(0.64$ to 1.67$)$ \\
\hline Q4 & 1.67 (1.12 to 2.49$)$ & 1.10 (0.86 to 1.39$)$ & 0.94 (0.58 to 1.52$)$ & 1.69 (1.13 to 2.52$)$ & 1.09 (0.86 to 1.39$)$ & 0.82 (0.51 to 1.34$)$ \\
\hline Q5 (least deprived) & 1.00 & 1.00 & 1.00 & 1.00 & 1.00 & 1.00 \\
\hline
\end{tabular}

* Model 2 for self-reported family income is adjusted for all variables in model 1 plus neighbourhood income; model 2 for neighbourhood income level is adjusted for all variables in model 1 plus family income; model 2 for material deprivation is adjusted for all variables in model 1 plus self-reported family income. Normal weight $(-2 \leq \mathrm{ZBMI} \leq 1)$ is the reference category for the dependent variable.

BMI, body mass index; \$C, Canadian dollars; zBMI, BMI z-scores. 
Table 3 Multilevel multinomial logistic regression model for the discordant and concordant categories of family income, neighbourhood income and deprivation in relation to underweight, overweight and obesity categories compared with normal weight in children aged 0-12 years

\begin{tabular}{|c|c|c|c|}
\hline \multirow[b]{2}{*}{ Exposure variable } & \multicolumn{3}{|c|}{$\begin{array}{l}\text { Model } 1 \text { (adjusted for child age, sex, number of family members, maternal ethnicity) } \\
\text { OR }(95 \% \mathrm{Cl})\end{array}$} \\
\hline & Underweight $(\mathrm{zBMI}<-2)$ & Overweight $(1<\mathrm{zBMI} \leq 2)$ & Obesity $(\mathrm{zBMI}>2)$ \\
\hline \multicolumn{4}{|c|}{ Family income and neighbourhood income } \\
\hline Low and low & $0.94(0.58$ to 1.52$)$ & $1.36(0.99$ to 1.86$)$ & $3.28(2.08$ to 5.18$)$ \\
\hline Low and higher & 0.77 (0.48 to 1.22$)$ & $0.92(0.68$ to 1.25$)$ & 2.05 (1.32 to 3.19$)$ \\
\hline Higher and low & $0.95(0.62$ to 1.46$)$ & $0.76(0.56$ to 1.04$)$ & $1.37(0.84$ to 2.24$)$ \\
\hline Higher and higher & 1.00 & 1.00 & 1.00 \\
\hline \multicolumn{4}{|c|}{ Family income and neighbourhood deprivation } \\
\hline Low and low* & $0.83(1.49$ to 1.42$)$ & 1.61 (1.15 to 2.24$)$ & $3.39(2.09$ to 5.50$)$ \\
\hline Low and higher & 0.83 (0.54 to 1.27$)$ & 0.91 (0.68 to 1.21$)$ & 2.14 (1.41 to 3.23$)$ \\
\hline Higher and low & $0.81(0.46$ to 1.42$)$ & 0.91 (0.63 to 1.31) & $1.61(0.90$ to 2.91$)$ \\
\hline Higher and higher & 1.00 & 1.00 & 1.00 \\
\hline
\end{tabular}

Underweight $=z \mathrm{BMI}<-2$, normal weight $=-2 \leq \mathrm{ZBMI} \leq 1$, overweight $=1<\mathrm{BM} \leq \mathbf{2}$. Normal weight is the reference category for the dependent variable.

*Low was defined as Q1 and higher was defined as Q2-Q5, where low deprivation score represents the most deprived. The multiplicative interaction between family and neighbourhood income had a p value of 0.09 and for family income and deprivation the $p$ value for interaction was 0.12 .

$\mathrm{BMI}$, body mass index; zBMI, BMI z-scores.

participate as participants with high income and without obesity. Therefore, for our observed ORs of 4.69, 2.18 and 2.45, for each exposure of interest, the corresponding selection bias-adjusted ORs would be 7.53, 3.51 and 3.93, respectively. These results suggest that even if there is strong selection bias (in the direction that children from low-income families who had obesity were less likely to participate than children from low-income families without obesity), our results are likely biased towards the null. This suggests our results might underestimate the true magnitude of the association between low income and obesity. Further, using the E-value formula to evaluate uncontrolled or unmeasured confounding, we find that for our observed OR of 4.69 (95\% CI 2.65 to 8.29 ) for the association between family income and obesity, the E-value would be 8.9 with a lower limit of the $95 \%$ CI of 4.7 . This suggests that a very strong unmeasured confounder would be needed to explain away the observed association, that is, the observed OR of 4.69 could be explained away by an unmeasured confounder that was associated with both the exposure and the outcome by an OR of 8.9.

The weighted kappa statistics suggest low agreement between family-level and neighbourhood-level income $(0.25,95 \% \mathrm{CI}$ 0.24 to 0.27 ) and family-level income and material deprivation $(0.28,95 \%$ CI 0.26 to 0.30$)$ (table 4$)$. As anticipated, the agreement between neighbourhood-level income and neighbourhood deprivation was somewhat stronger since neighbourhood-level income is one component of the neighbourhood deprivation index $(0.51,95 \%$ CI 0.50 to 0.53$)$.

\section{DISCUSSION}

The overall findings of our study suggest that among young children recruited from primary care in the Greater Toronto Area in Canada, low family-level income, low neighbourhood-level income and neighbourhood deprivation are strongly associated

Table 4 Agreement between measures of family income, neighbourhood income and material deprivation

\begin{tabular}{ll}
\hline & Weighted kappa $(95 \% \mathrm{CI})$ \\
\hline Family income and neighbourhood income & $0.25(0.24$ to 0.27$)$ \\
\hline Family income and material deprivation & $0.28(0.26$ to 0.30$)$ \\
\hline Neighbourhood income and material deprivation & $0.51(0.50$ to 0.53$)$
\end{tabular}

with child obesity with adjusted OR estimates suggesting a 2-5-fold increased risk. This is larger than many other known behavioural and nutritional risk factors for child obesity. ${ }^{28}$

Further, our results suggest that family-level income has the strongest association and remains an independent predictor after adjusting for neighbourhood income. In contrast, the associations between both neighborhood-level income and neighbourhood deprivation and child obesity were attenuated when adjusted for family-level income. We also report that the agreement between both family income and neighbourhood income and between family income and neighbourhood deprivation was quite low in our population, emphasising that family-level and neighbourhood-level SES measure different constructs and might not be proxies of each other.

Given the extensive use of income measures in health equity studies in children, the associations between individual-level or family-level income versus area-level income and child obesity need to be delineated. Studies from other countries that have simultaneously examined the association between both arealevel and individual-level risk factors and child BMI in children and youth provide consistent support for independent effects of neighbourhood-level SES factors after adjusting for family-level SES factors. ${ }^{29-32}$ There are numerous possible mechanisms that may explain why children in low-income families are more likely to have obesity, including healthy food affordability and access (eg, inadequate grocery stores in low-income neighbourhoods), access to recreational programmes and/or the built environment of their neighbourhood is not conducive towards an active lifestyle (eg, no playgrounds, walkways, etc). Future studies of childhood obesity should consider investigating these potential risk factors directly instead of neighbourhood SES which is a proxy for many things. Further, results of past studies were not stratified by sex, which has become increasingly important with the knowledge that the aetiology and trajectory of obesity differs in girls and boys ${ }^{33} 34$; however, our results do not provide strong evidence of sex differences in the association between SES and child obesity and larger sample sizes may be needed. As there is also considerable evidence for the association between contextual neighbourhood factors and health, past literature has attempted to disentangle contextual factors from individual risk factors in an attempt to better inform population health interventions. $^{35}$ 
The low agreement between family income and both neighbourhood-level income and neighbourhood deprivation is consistent with previous studies. ${ }^{671011}$ Previous literature has primarily focused on determining the impact of area-level measures of SES on BMI, over and above family-level and individual measures, and does not provide adequate comparisons of the two different income measures. Two of the US studies also produced misclassification rates of $20 \%$ and $31 \%$, whereas the sole Canadian study produced a misclassification rate of $80 \%$, much higher than what was observed in the USA. This is not an unusual finding as neighbourhoods in Toronto are much more structurally heterogenous than their southern counterparts. ${ }^{36}$

Strengths of this study include the relatively large sample of young children and the physical measurement of height and weight by trained research assistants. Further, the availability of both family-level and neighbourhood-level measures is a strength. Stratification by sex is also a strength of this study and it is possible that sex differences do exist although we may not have had sufficient power to assess. Potential limitations of this study include the cross-sectional study design although reverse causation seems unlikely it is a possibility. Our study cohort is skewed towards a highincome and highly educated population, which may limit generalisability of these results and may underestimate the true association between income and obesity. However, of greater concern is the potential for selection bias; weight stigma and bias are serious concerns and limit participation in research and healthcare seeking. Since this population was recruited from primary care, it is possible that there may be strong differential selection bias in that children with obesity and from low-income families may be the least likely to participate. The potential impact of selection bias on our study was investigated through a simple quantitative bias analysis using national data among older children for comparison which suggests that children from low-income families with obesity may have been less likely to participate in our study compared with children with low-income families and no obesity. The quantitative bias analysis suggests that our results likely underestimate the true association (ie, our results may be biased towards the null). As with all observational studies, misclassification error and residual confounding may also be present, but we do not think these would be the major sources of bias. Both income and zBMI were categorised for this analysis which limits power and has inherent limitations but was done to maintain a definition of obesity consistent with public health and clinical practice and to show possible non-linear associations. When considering the external validity of this study, it is important to recognise that this was not a population-based sample and may not be representative of the source population. Further, the 'low' family income category was defined as less than the first quintile which was $\$ 70244$ and this is relatively high for our population. The low-income measure threshold for before-tax income for a family of four in Toronto was defined as \$51031 in 2015. ${ }^{37}$

Although the rates of child obesity have stabilised in recent years in North America, child obesity remains a significant public health concern. It is evident that the burden of obesity is increasing among children with lower SES and public health initiatives need to take special consideration of such population groups. ${ }^{38}$ A recent review found limited evidence that child obesity interventions may reduce socioeconomic inequalities at the individual level, but evidence for community-level or societal-level interventions was inconclusive. ${ }^{39}$ In public

\section{What is already known on this subject}

$\Rightarrow$ Socioeconomic factors are important determinants of childhood obesity. However, the independent and joint associations between family-level income neighbourhoodlevel income and neighbourhood deprivation, with child obesity among young children in Canada, are unknown.

\section{What this study adds}

$\Rightarrow$ As a result of this study we now know that in our relatively affluent urban population, family-level income was a strong independent risk factor for child obesity. Further, neighbourhood income and deprivation were also strong risk factors and children from lower-income families living in low-income neighbourhoods were at the greatest risk. Individual-level and neighbourhood-level measures of income are independent and should both be addressed in childhood obesity interventions.

health research, particular emphasis should be placed on SES and child health outcomes because the gradient between SES and health is known to widen with age and early childhood is a critical period in development. The results demonstrated that individual-level income was most strongly and independently associated with child obesity, however, a joint measure suggests that neighbourhood-level SES also matters in our urban setting. Therefore, in addition to individual-level socioeconomic variables, obesity prevention strategies should also consider neighbourhood-level variables and neighbourhood interventions directed at low-income families may be a helpful tool for preventing disparities in child obesity.

Twitter Laura N Anderson @AndersonLauraN

Collaborators The TARGet Kids! Collaboration.

Contributors LNA, TF, BShah and CDGK-S contributed to the statistical analysis. AF, CMB, BSmith, LNA, JM and CB contributed to the design and interpretation of study results. All authors read and revised the manuscript.

Funding Funding for this study was obtained from the Canadian Institutes of Health Research.

Competing interests None declared.

Patient consent for publication Not required.

Ethics approval This study was approved by the Research Ethics Board at the Hospital for Sick Children (REB-1000012436) and St. Michael's Hospital, Toronto, Canada, and written informed consent was obtained from parents of all participating children.

Provenance and peer review Not commissioned; externally peer reviewed.

Data availability statement Data are available upon reasonable request. Data are available upon request by contacting www.targetkids.ca/contact-us/ . The full data are not freely available to respect the confidentiality of our participants, ensure data integrity, and avoid scientific overlap between projects. Once initial contact has been made, we request a short research proposal which will be subject to review by the TARGet Kids! Scientific Committee and approval by institutional research ethics boards.

Supplemental material This content has been supplied by the author(s). It has not been vetted by BMJ Publishing Group Limited (BMJ) and may not have been peer-reviewed. Any opinions or recommendations discussed are solely those of the author(s) and are not endorsed by BMJ. BMJ disclaims all liability and responsibility arising from any reliance placed on the content. Where the content includes any translated material, BMJ does not warrant the accuracy and reliability of the translations (including but not limited to local regulations, clinical guidelines, 
terminology, drug names and drug dosages), and is not responsible for any error and/or omissions arising from translation and adaptation or otherwise.

Open access This is an open access article distributed in accordance with the Creative Commons Attribution Non Commercial (CC BY-NC 4.0) license, which permits others to distribute, remix, adapt, build upon this work non-commercially, and license their derivative works on different terms, provided the original work is properly cited, appropriate credit is given, any changes made indicated, and the use is non-commercial. See: http://creativecommons.org/licenses/by-nc/4.0/.

\section{ORCID iDs}

Laura N Anderson http://orcid.org/0000-0002-6106-5073

Brendan T. Smith http://orcid.org/0000-0003-2785-1246

Anne E. Fuller http://orcid.org/0000-0001-5930-5317

\section{REFERENCES}

1 Rodd C, Sharma AK. Recent trends in the prevalence of overweight and obesity among Canadian children. CMAJ 2016;188:E313-20.

2 Fryar CD, Carroll MD, Ogden CL. Prevalence of overweight, obesity, and severe obesity among children and adolescents aged 2-19 years: United States, 1963-1965 through 2015-2016 2018

3 Anderson LN, Ball GDC. Physical activity, and behavioural interventions for the treatment of overweight or obesity in children and adolescents. Paediatr Child Health 2019.

4 Pereira MMCE, Padez CMP, Nogueira HGdaSM. Describing studies on childhood obesity determinants by socio-ecological model level: a scoping review to identify gaps and provide guidance for future research. Int J Obes 2019;43:1883-90.

5 Wu S, Ding Y, Wu F, et al. Socio-economic position as an intervention against overweight and obesity in children: a systematic review and meta-analysis. Sci Rep 2015:5:11354.

6 Buajitti E, Chiodo S, Rosella LC. Agreement between area- and individual-level income measures in a population-based cohort: implications for population health research. SSM Popul Health 2020;10:100553.

7 Erdle SC, Birken CS, Parkin PC, et al. Poor agreement between family-level and neighborhood-level income measures among urban families with children. J Clin Epidemiol 2014;67:838-40.

8 Robert SA, Reither EN. A multilevel analysis of race, community disadvantage, and body mass index among adults in the US. Soc Sci Med 2004;59:2421-34.

9 Mustard CA, Derksen S, Berthelot JM, et al. Assessing ecologic proxies for household income: a comparison of household and neighbourhood level income measures in the study of population health status. Health Place 1999;5:157-71.

10 Narla NP, Pardo-Crespo MR, Beebe TJ, et al. Concordance between individual vs. arealevel socioeconomic measures in an urban setting. J Health Care Poor Underserved 2015:26:1157-72.

11 Pardo-Crespo MR, Narla NP, Williams AR, et al. Comparison of individual-level versus area-level socioeconomic measures in assessing health outcomes of children in Olmsted County, Minnesota. J Epidemiol Community Health 2013;67:305-10.

12 McKenzie TL, Moody JS, Carlson JA, et al. Neighborhood income matters: disparities in community recreation facilities, amenities, and programs. J Park Recreat Admi 2013;31:12-22.

13 Christian H, Zubrick SR, Foster S, et al. The influence of the neighborhood physical environment on early child health and development: a review and call for research. Health Place 2015;33:25-36.

14 Matheson FI, Dunn JR, Smith KLW. Development of the Canadian marginalization index: a new tool for the study of inequality. Can J Public Health Rev Can Santee Publique 2012;103:S12-16 https://www.jstor.org/stable/41995683

15 Hails KA, Shaw DS. Associations between boys' early childhood exposure to family and neighborhood poverty and body mass index in early adolescence. $J$ Pediatr Psychol 2019:44:1009-18.
16 Carsley S, Borkhoff CM, Maguire JL, et al. Cohort profile: the applied research group for kids (TARGet Kids!). Int J Epidemiol 2015;44:776-88.

17 Hunter DJ, Drown M. Binsmooth: generate PDFs and CDFs from binned data. R package version 0.2.2, 2020. Available: https://CRAN.R-project.org/package= binsmooth

18 von Hippel P, Hunter D, Drown M. Better estimates from binned income data: Interpolated CDFs and Mean-Matching. Sociol Sci 2017;4:641-55.

19 Canada S. Postal code conversion file (PCCF). Reference Guide 2017:92:23.

20 Matheson F, van Ingen T. Ontario marginalization index: user guide. St. Michael's Hospital, 2018. https://www.publichealthontario.ca/en/Data and Analysis/Health Equity/Ontario Marginalization Index

21 Onis M, WHO Multicentre Growth Reference Study Group. Who child growth standards based on length/height, weight and age: who child growth standards. Acta Paediatr 2007:95:76-85.

22 Satkunam M, Anderson LN, Carsley S, et al. Severe obesity in children 17 to 24 months of age: a cross-sectional study of TARGet Kids! and Better Outcomes Registry \& Network (BORN) Ontario. Can J Public Health 2018;109:489-97.

23 Furlong $\mathrm{KR}$, Anderson LN, Kang $\mathrm{H}$, et al. BMI-for-age and weight-for-length in children 0 to 2 years. Pediatrics 2016;138:e20153809.

24 Shah B, Tombeau Cost K, Fuller A, et al. Sex and gender differences in childhood obesity: contributing to the research agenda. BMJ Nutr Prev Health 2020;3:bmjnph2020-000074:387-90.

25 SAS Institute Inc. Sas university edition. Cary, NC, USA.

26 Lash TL, Fox MP, MacLehose RF, et al. Good practices for quantitative bias analysis. Int J Epidemiol 2014;43:1969-85.

27 VanderWeele TJ, Ding P. Sensitivity analysis in observational research: introducing the E-Value. Ann Intern Med 2017:167:268-74.

28 Poorolajal J, Sahraei F, Mohamdadi Y, et al. Behavioral factors influencing childhood obesity: a systematic review and meta-analysis. Obes Res Clin Pract 2020;14:109-18.

29 Janssen I, Boyce WF, Simpson K, et al. Influence of individual- and area-level measures of socioeconomic status on obesity, unhealthy eating, and physical inactivity in Canadian adolescents. Am J Clin Nutr 2006;83:139-45.

30 Oliver LN, Hayes MV. Effects of neighbourhood income on reported body mass index: an eight year longitudinal study of Canadian children. BMC Public Health 2008;8:16.

31 Li X, Memarian E, Sundquist J, et al. Neighbourhood deprivation, individuallevel familial and socio-demographic factors and diagnosed childhood obesity: a nationwide multilevel study from Sweden. Obes Facts 2014;7:253-63.

32 Schüle SA, von Kries R, Fromme H, et al. Neighbourhood socioeconomic context, individual socioeconomic position, and overweight in young children: a multilevel study in a large German City. BMC Obes 2016;3:25.

33 Wisniewski AB, Chernausek SD. Gender in childhood obesity: family environment, hormones, and genes. Gend Med 2009;6:76-85.

34 Sweeting HN. Gendered dimensions of obesity in childhood and adolescence. Nutr J 2008;7:1.

35 Perdue WC, Stone LA, Gostin LO. The built environment and its relationship to the public's health: the legal framework. Am J Public Health 2003:93:1390-4.

36 Oreopoulos P. Neighbourhood Effects in Canada:A Critique. Canadian Public Policy 2008:34:237-58

37 Statistics Canada. Low-income measures thresholds (LIM-AT and LIM-BT) for private households of Canada, 2015, 2016. Available: https://www12.statcan.gc.ca/censusrecensement/2016/ref/dict/tab/t4 2-eng.cfm [Accessed 21 June 2019].

38 Lee $\mathrm{H}$, Andrew M, Gebremariam A, et al. Longitudinal associations between poverty and obesity from birth through adolescence. Am J Public Health 2014;104:e70-6.

39 Hillier-Brown FC, Bambra CL, Cairns J-M, et al. A systematic review of the effectiveness of individual, community and societal level interventions at reducing socioeconomic inequalities in obesity amongst children. BMC Public Health 2014;14:834. 